\title{
International Study of Asthma and Allergies in Childhood: phase 3 in the Syrian Arab Republic
}

\author{
Y. Mohammad, ${ }_{1}^{1}$ K. Tabbah, ${ }^{2}$ S. Mohammad, ${ }^{3}$ F. Yassine, ${ }^{1}$ T. Clayton ${ }^{4}$ and M. Hassan ${ }^{5}$
}

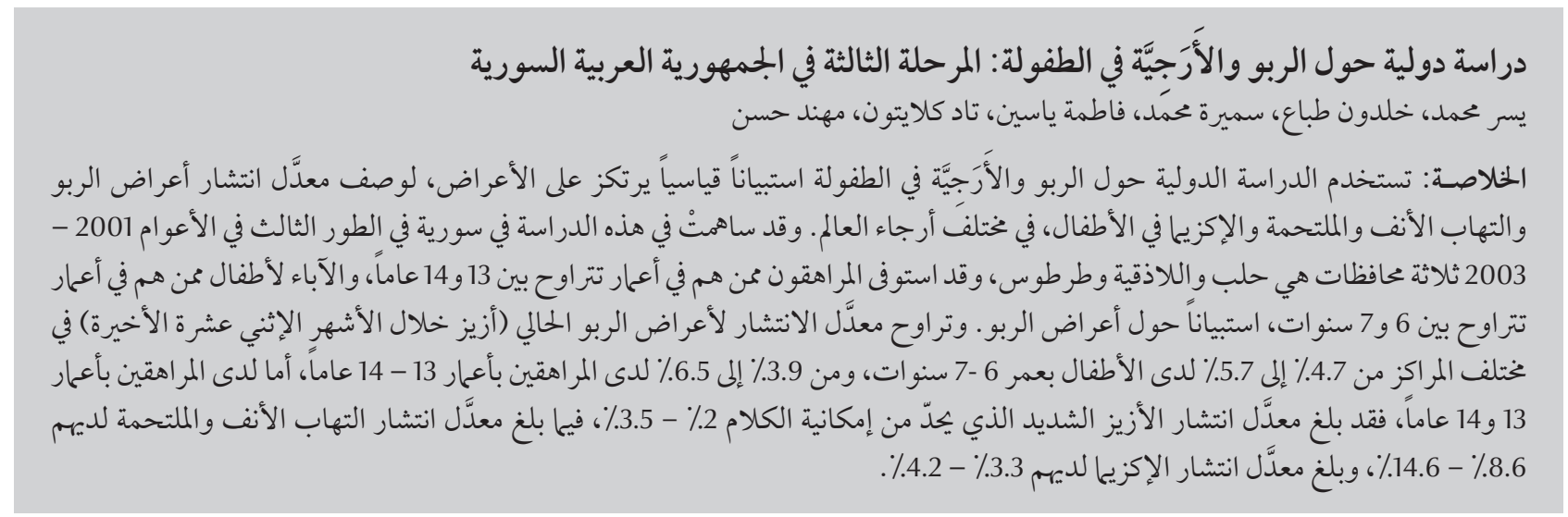

ABSTRACT The International Study of Asthma and Allergies in Childhood (ISAAC) uses standardized symptombased questionnaires to describe the prevalence of symptoms of asthma, rhinoconjunctivitis and eczema in children worldwide. Three governorates in the Syrian Arab Republic (Aleppo, Lattakia and Tartous) participated in ISAAC phase 3 in 2001-03. Adolescents in the 13-14 year age group and parents of the 6-7-year-old children completed the questionnaire about asthma symptoms. The prevalence of current symptoms of asthma (wheezing in the last 12 months) in different centres ranged from 4.7\% to 5.7\% for 6 -7-year-olds and $3.9 \%$ to $6.5 \%$ for $13-14$-year-olds. In 13-14-year-olds the prevalence of severe speech-limiting wheeze was $2.0 \%-3.5 \%$, of rhinoconjunctivitis was $8.6 \%-14.6 \%$ and of eczema was $3.3 \%-4.2 \%$.

\section{Étude internationale de l'asthme et des allergies de l'enfant : phase 3 en République arabe syrienne}

RÉSUMÉ L'étude internationale de l'asthme et des allergies de l'enfant (ISAAC) utilise des questionnaires standardisés basés sur les symptômes de l'asthme, de la rhinoconjonctivite et de l'eczéma touchant les enfants dans le monde entier. Entre 2001 et 2003, trois gouvernorats de la République arabe syrienne (Alep, Lattaquié et Tartous) ont participé à la phase 3 de I'ISAAC. Les adolescents appartenant à la tranche d'âge 13-14 ans et les parents d'enfants âgés de 6 à 7 ans ont rempli le questionnaire concernant les symptômes de l'asthme. La prévalence des symptômes actifs de l'asthme (sifflement respiratoire au cours des 12 derniers mois) dans différents hôpitaux était comprise entre 4,7 \% et 5,7 \% pour les enfants âgés de 6 à 7 ans et entre 3,9 \% et 6,5\% pour ceux âgés de 13 à 14 ans. Au sein du groupe des 13-14 ans, la prévalence du sifflement respiratoire sévère limitant la parole était comprise entre 2,0 \% et 3,5\%, celle de la rhinoconjonctivite variait entre 8,6 \% et 14,6 \% et celle de l'eczéma oscillait entre 3,3\% et 4,2\%.

${ }^{7}$ Department of Internal Medicine, ${ }^{5}$ High Institute of Maritime Research, Tishreen University, Lattakia, Syrian Arab Republic (Correspondence to Y.Mohammad:mohamyou@scs-net.org).

${ }^{2}$ Department of Internal Medicine, Pulmonary Section, University of Aleppo, Aleppo, Syrian Arab Republic. ${ }^{3}$ Department of Paediatrics, Military Health Services, Lattakia, Syrian Arab Republic.

${ }^{4}$ Department of Paediatrics: Child and Youth Health, The University of Auckland, Auckland, New Zealand.

Received: 02/10/08; accepted: 11/12/08 


\section{Introduction}

There is a wide consensus that the prevalence of asthma and allergies are on the increase among children worldwide [1]. In some industrialized countries, asthma and allergies have reached alarming proportions, affecting up to one-third of children within the general population [2]. While the prevalence of asthma has been well-documented in the past 30 years, variations in study methods and the lack of uniform diagnostic criteria make direct comparison between studies difficult. In addition, few of the studies of prevalence were completed in developing countries. The International Study of Asthma and Allergies in Childhood (ISAAC) is a collaborative project which has developed a standardized methodology to describe the prevalence and severity of symptoms of asthma, rhinoconjunctivitis and eczema in children throughout the world $[3,4]$.

The aim of ISAAC is to compare the prevalence of allergic disorders between populations in different countries by using standard validated questions, thereby providing a framework for research into possible modifiable lifestyle and environmental factors affecting these disorders that may ultimately lead to a reduction in the personal burden of allergic diseases $[3,4]$. Many centres from developing countries were able to participate in ISAAC because of the simplicity of the questionnaires [4]. The data collected by ISAAC provides a unique illustration of the prevalence of current symptoms of asthma, rhinoconjunctivitis and eczema in children and adolescents worldwide [5].

ISAAC Phase One (1992-97) provided standardized data concerning the prevalence of symptoms of asthma, rhinoconjunctivitis and eczema from 156 centres in 56 countries. ISAAC Phase Three was a repeat of Phase One to investigate the trends in the prevalence of allergic diseases in centres which participated in Phase One (ISAAC Phase Two was a more intensive study which examined objective markers of asthma and allergies in children living in specific centres [6]). New centres were also accepted in Phase Three in order to extend the database of prevalence around the world. The survey included 238 participating centres from 98 countries including 3 centres from the Syrian Arab Republic $[7,8]$. This paper reports data on the prevalence and burden of asthma and other atopic diseases from the Syrian centres in order to provide a basis for present and future national and international comparisons.

\section{Methods}

\section{Study areas}

The 3 centres in the Syrian Arab Republic (Aleppo, Lattakia and Tartous) that participated in ISAACPhase Three were chosen primarily because enthusiastic researchers were present in each centre, but also because the centres provided some interesting contrasts: Aleppo has a very dry climate, while Lattakia and Tartous are both located in coastal areas and Tartous experiences considerable air pollution from industrial activities (e.g. oil refineries).

The study in Aleppo was carried out in April 2001. The study in Lattakia was carried out in February and March 2003 for the 6-7-year-olds, and from April 2001 to November 2002 for the 13-14-year-olds. The study in Tartous was carried out from March 2001 to November 2002 for the 6-7-year-olds, and from April 2001 to October 2002 for 13-14-year-olds.

\section{Sample}

For ISAAC Phase Three a sample of 3000 13-14-year-olds was mandatory for all centres and a second sample of 3000 6-7-year-olds was optional. The ISAAC steering committee calculated that a sample size of 3000 was necessary to be representative of children within thegeneralpopulationandtoprovidesufficient power for the study [9]. The core questionnaire was mandatory, while the video questionnaire (13-14-year-age group only) and the environmental questionnaire were recommended but optional due to expected difficulties in some low-income countries [10].

In Lattakia, Tartous and Aleppo, schools were randomly selected to ensure that the sample of schools was representative of the wider community. The number of schools surveyed for the 13-14 year age group was 14 for Tartous, 13 for Lattakia and 11 for Aleppo. For the 6-7 year age group 24 schools were surveyed in Tartous and 16 in Lattakia (Aleppo included only the 13-14-year-olds). All pupils in the class and age range were approached. A second visit was made to the schools if necessary to recruit students absent at the initial visit.

Ethical approval for the study was given by the Ministry of Higher Education and the Ministry of Education.

\section{Questionnaires}

A questionnaire with separate modules for symptoms of asthma, rhinoconjunctivitis and eczema was designed for ISAAC Phase One and Phase Three, and administered to pupils aged 6-7 years and 13-14 years [9]. The questionnaires were designed by the ISAAC steering committee and have been validated for specificity and sensitivity [9]. Phase Three also including an optional environmental questionnaire which examined etiological factors. Students aged 13-14 years responded in the classroom to a self-administered 8-page questionnaire (Arabic version) after a brief written and verbal explanation from the research staff under examination conditions. For the 6-7 year age group, parents were met by the research team and filled in the core and environmental questionnaires but not the video questionnaire.

The main outcome measures in this study, obtained from responses to the core questionnaires, were the current prevalence of symptoms of asthma 
(wheezing in the last 12 months), rhinoconjunctivitis and eczema. Standard ISAAC definitions were used: asthma (wheezing or whistling in the chest); current rhinoconjunctivitis (a problem with sneezing or a runny or blocked nose when you did not have a cold or flu and accompanied by itchy, watery eyes); and eczema (itchy rash at any time affecting folds of the elbows, behind the knees, in front of the ankles, under the buttocks or around the neck, ears or eyes). The degree of control and severity of wheeze was also measured by the core questionnaire. Persistency of symptoms and uncontrolled chronic disease is measured by sleep disturbance (been woken by asthma symptoms in the last 12 months), while severe episodes are indicated by attacks of speech-limiting wheeze.

As recommended by the ISAAC protocol, the core questionnaire was followed by an optional video questionnaire for the 13-14 year age group. The rationale for the video questionnaire was that by showing rather than describing the signs and symptoms of asthma to children, the video questionnaire would provide more accurate recognition of clinical asthma symptoms and allow more confidence in comparisons between populations with different cultures and languages. The video showed 5 sequences related to asthma symptoms and severity. After viewing each sequence, participants answered specific questions about moderate wheezing at rest; wheezing and shortness of breath after exercise; nocturnal wheezing; nocturnal cough; and severe wheezing and shortness of breath at rest.

The environmental questionnaire was included in all 3 Syrian centres. A detailed analysis of the data will be presented in a subsequent paper.

\section{Analysis}

Prevalence values were generated at the ISAAC international data centre in Auckland, New Zealand, and analysed using SAS, version 9. Additional analyses were completed in the Syrian Arab Republic to examine the agreement between the written and video questionnaires.

\section{Results}

The response rate was $99.5 \%$ for the 6-7 year age group and $98.0 \%$ for the 13-14 year age group. Details of the demographic characteristics of the centres are presented in Tables 1 and 2. The data from the 3 centres together included more females than males, with $48.6 \%$ males for the 6-7 year age group and $44.6 \%$ males for the 13-14 year age group. There were statistically significant differences between the centres in the age and sex distribution of respondents within each age group (Tables 1 and 2).

\section{Core written questionnaire}

The prevalence of current symptoms of asthma (wheezing in the last 12 months) in the 6-7 years age group were $5.7 \%$ and $4.7 \%$ in Tartous and Lattakia respectively. For current symptoms of rhinoconjunctivitis the figures were $5.0 \%$ and $2.4 \%$ and for current symptoms of eczema $2.7 \%$ and $3.9 \%$ (Table 3). The prevalence of current symptoms of asthma (wheezing in the last 12 months) in 13-14-year-olds were $3.9 \%, 6.5 \%$ and $5.1 \%$ in Tartous, Lattakia and Aleppo respectively. The corresponding figures for rhinoconjunctivitis were $8.6 \%, 10.1 \%$ and $14.6 \%$ and for eczema were $4.2 \%, 3.3 \%$ and $4.1 \%$ (Table 4 ).

The prevalence ofseverespeech-limiting wheeze in the last 12 months for the 6-7-year-olds were $2.3 \%$ and $2.0 \%$ from Tartous and Lattakia respectively and for 13 -14-year-olds were $2.2 \%, 3.5 \%$ and $2.0 \%$ from Tartous, Lattakia and Aleppo respectively (Tables 3 and 4).

The prevalence of sleep disturbance for 6-7-year-olds was 5.3\% and 2.9\% for Lattakia and Tartous respectively and for 13-14-year-olds was $4.5 \%, 3.2 \%$ and 2.6\% for Lattakia, Tartous and Aleppo respectively (Tables 3 and 4 ).

\section{Video questionnaire}

In the 13-14-year-olds the prevalence of symptoms of asthma, rhinoconjunctivitis and eczema were different based on the video questionnaire (Table 5) than the written core questionnaire

\begin{tabular}{|c|c|c|c|c|c|c|}
\hline \multirow[t]{2}{*}{ Variable } & \multicolumn{2}{|c|}{ Tartous $(\boldsymbol{n}=\mathbf{2 7 3 4})$} & \multicolumn{2}{|c|}{ Lattakia $(n=2373)$} & \multicolumn{2}{|c|}{ Total $(n=5107)$} \\
\hline & No. & $\%$ & No. & $\%$ & No. & $\%$ \\
\hline \multicolumn{7}{|c|}{ Age $(\text { years })^{a}$} \\
\hline 6 & 1925 & 81.1 & 988 & 36.1 & 2913 & 57.0 \\
\hline 7 & 448 & 18.9 & 1745 & 63.8 & 2193 & 42.9 \\
\hline 8 & - & - & 1 & 0.0 & 1 & 0.0 \\
\hline \multicolumn{7}{|l|}{$\operatorname{Sex}^{a}$} \\
\hline Male & 1093 & 46.1 & 1390 & 50.8 & 2483 & 48.6 \\
\hline Female & 1280 & 53.9 & 1344 & 49.2 & 2624 & 51.4 \\
\hline
\end{tabular}

${ }^{a}$ Chi-squared test for difference between centres, $P<0.001$. 


\begin{tabular}{|c|c|c|c|c|c|c|c|c|}
\hline \multirow[t]{2}{*}{ Variable } & \multicolumn{2}{|c|}{ Tartous $(n=2995)$} & \multicolumn{2}{|c|}{ Lattakia $(n=3010)$} & \multicolumn{2}{|c|}{ Aleppo $(n=3063)$} & \multicolumn{2}{|c|}{ Total $(n=9068)$} \\
\hline & No. & $\%$ & No. & $\%$ & No. & $\%$ & No. & $\%$ \\
\hline \multicolumn{9}{|l|}{ Age (years) ${ }^{a}$} \\
\hline 11 & - & - & - & - & 152 & 5.0 & 152 & 1.7 \\
\hline 12 & 1 & 0.0 & - & - & 971 & 31.7 & 972 & 10.7 \\
\hline 13 & 2201 & 73.5 & 2088 & 69.4 & 1347 & 44.0 & 5636 & 62.2 \\
\hline 14 & 793 & 26.5 & 922 & 30.6 & 496 & 16.2 & 2211 & 24.4 \\
\hline 15 & - & - & - & - & 91 & 3.0 & 91 & 1.0 \\
\hline 16 & - & - & - & - & 4 & 0.1 & 4 & 0.0 \\
\hline Missing data & - & - & - & - & 2 & 0.0 & 2 & 0.0 \\
\hline \multicolumn{9}{|l|}{$\operatorname{Sex}^{a}$} \\
\hline Male & 1420 & 47.4 & 1075 & 35.7 & 1551 & 50.6 & 4046 & 44.6 \\
\hline Female & 1575 & 52.6 & 1935 & 64.3 & 1512 & 49.4 & 5022 & 55.4 \\
\hline
\end{tabular}

${ }^{a}$ Chi-squared test for difference between centres, $P<0.001$.

(Table 4). However the prevalence of the main outcome measure-wheezing in the last 12 months - from the video questionnaire was similar to the written questionnaire: 3.9\% for Tartous, 5.1\% for Lattakia and 6.2\% for Aleppo.

Agreement between the written and video questionnaires in the 3 Syrian centres combined was assessed using the kappa coefficient. This analysis was based only on those pupils who responded to both the video and written questionnaires. The kappa values were: for wheezing in the last 12 months $\kappa=$ 0.22 , for ever wheezing $\kappa=00.20$, for exercise wheeze $\kappa=0.05$, for nocturnal cough $\kappa=0.06$ and for severe episodes $\kappa=0.19$. Once again, we found the best agreement was for current wheeze.

\section{Comparisons between centres}

For the 6-7 year age group there was a general pattern for Lattakia to show a lower prevalence of symptoms than Tartous but this was only statistically significant for ever wheezing [odds ratio $0.62,95 \%$ confidence interval: 0.45-0.86] (Table 3). For the 13-14 year age group written questionnaire the pattern was reversed, with Lattakia generally showing a higher prevalence of symptoms than Tartous. For the majority of symptoms the difference was statistically significant (Table 4). The prevalence values for Aleppo were by and large intermediate between Tartous and Lattakia, with the exception of night cough and rhinoconjunctivitis, for which Aleppo showed a higher prevalence than Tartous and Lattakia (Table 4). From the video questionnaire for the 13-14-year-age group Lattakia again showed generally higher symptom prevalencesthan Tartous,althoughonly current wheeze and current exercise

\begin{tabular}{|c|c|c|c|c|c|c|c|}
\hline \multirow[t]{2}{*}{ Variable } & \multicolumn{2}{|c|}{ Tartous $(n=2734)^{\mathrm{a}}$} & \multicolumn{3}{|c|}{ Lattakia $(n=2373)$} & \multicolumn{2}{|c|}{ Total $(n=5107)$} \\
\hline & No. & $\%$ & No. & $\%$ & OR $(95 \% \mathrm{Cl})^{\mathrm{b}}$ & No. & $\%$ \\
\hline Wheezing ever & 317 & 11.6 & 188 & 7.9 & $0.62(0.45-0.85)$ & 505 & 9.9 \\
\hline Wheezing in the last 12 months & 156 & 5.7 & 111 & 4.7 & $0.76(0.51-1.13)$ & 267 & 5.2 \\
\hline Sleep disturbance & 146 & 5.3 & 69 & 2.9 & $0.17(0.11-0.27)$ & 215 & 4.2 \\
\hline $\begin{array}{l}\text { Severe wheeze in the last } \\
12 \text { months (speech-limiting) }\end{array}$ & 64 & 2.3 & 47 & 2.0 & $0.88(0.48-1.63)$ & 111 & 2.2 \\
\hline Exercise wheeze in the last 12 months & 113 & 4.1 & 62 & 2.6 & $0.58(0.30-1.11)$ & 175 & 3.4 \\
\hline Night cough in the last 12 months & 453 & 16.6 & 362 & 15.3 & $0.89(0.61-1.30)$ & 815 & 16.0 \\
\hline Asthma ever & 123 & 4.5 & 93 & 4.0 & $0.85(0.55-1.31)$ & 216 & 4.5 \\
\hline $\begin{array}{l}\text { Rhinoconjunctivitis symptoms } \\
\text { in the last } 12 \text { months }\end{array}$ & 137 & 5.0 & 95 & 2.4 & $0.82(0.55-1.23)$ & 232 & 2.5 \\
\hline $\begin{array}{l}\text { Eczema symptoms in the last } \\
12 \text { months }\end{array}$ & 73 & 2.7 & 56 & 3.9 & $0.89(0.54-1.46)$ & 129 & 4.2 \\
\hline
\end{tabular}

${ }^{a}$ Reference category (Lattakia versus Tartous); ${ }^{b}$ Adjusted for age and sex. $O R=$ odds ratio $; \mathrm{Cl}=$ confidence interval. 


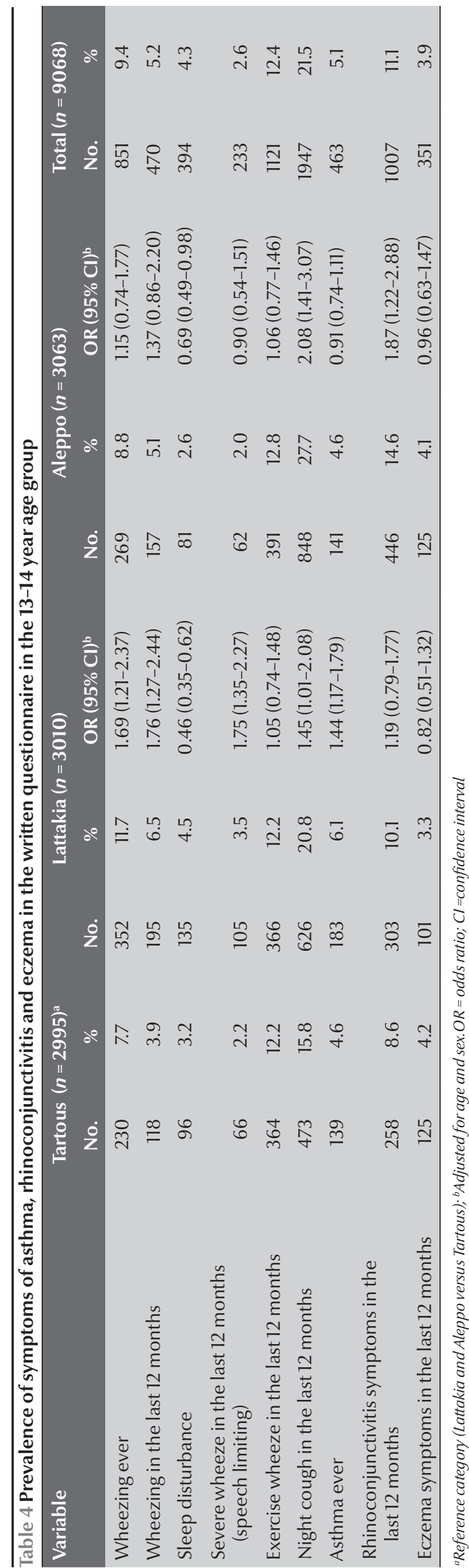

wheeze showed statistically significant differences (Table 5). However, in contrast to the written questionnaire, Aleppo in general showed higher prevalence values than Lattakia and Tartous (Table 5)

\section{Discussion}

Two large international studies-ISAAC in children and the European Community Respiratory Health Survey (ECRHS) in adults - have studied the prevalence of asthma and allergic rhinoconjunctivitis worldwide through the use of standardized questionnaires. Based on their results, there are approximately 300 million people with asthma worldwide, and asthma is the 25th ranked cause of a reduction in disability-adjusted life years [1].

ISAAC provides a unique opportunity for developing countries to participate in a multi-centre international study and the ISAAC survey in the Syrian Arab Republic has provided the first ever assessments of the prevalence of self-reported allergies in local children using standardized methods. Our study illustrates the burden of atopic diseases in Syrian schoolchildren. Based on the written questionnaire, the prevalence of current symptoms of asthma defined as wheezing the last 12 months in different centres ranged from $4.7 \%-5.7 \%$ for 6-7-year-olds and $3.9 \%-6.5 \%$ for $13-14$-year-olds. These results form the basis for local, regional and international comparisons.

As a comparison, the prevalence of current symptoms of asthma among 13-14-year-olds in other countries of the Mediterranean, Middle East and North Africa who participated in ISAAC Phase Three was $14.6 \%$ in Malta, $10.4 \%$ in Morocco, $8.7 \%$ in Algeria, $13.2 \%$ in Islamic Republic of Iran, $11.7 \%$ in Pakistan and $7.6 \%$ in Kuwait [11]. Prevalence rates around the world range from 3.4\% in Albania to 31.2\% in the Isle of Man [11]. Analysis of time trends for countries who participated in Phase One and Phase Three showed that, while the prevalence of current symptoms of asthma appears to have reached a plateau in industrialized countries, it is increasing in developing countries $[5,11]$.

As noted earlier, there are differences between the Syrian centres with respect to climate (dry in Aleppo, coastal in Tartous and Lattakia) and exposure to air pollution (polluted in Tartous). However there were no obvious associations between these factors and the differences in prevalence of symptoms. The lowest prevalence values were generally found in Lattakia for the 6-7 year age group and in Tartous for the 13-14 year age group. The planned analysis of the environmental questionnaire data may provide further insight into factors that may be associated with the differences in prevalence of symptoms between the Syrian centres.

The Global Initiative for Asthma (GINA) Global burden of asthma 2004 report notes that although written questions 
about current wheeze are validated for a worldwide asthma prevalence survey, the airway hyper-responsiveness challenge tests in clinical practice are positive in only $50 \%$ of individuals reporting current wheeze [1]. This suggests that when wheezing is transient and very mild it does not have any significant impact on the individual patient and does not require clinical care. According to the GINA report an arbitrary figure of $50 \%$ of the prevalence of current wheezing in children (self-reported wheezing in the previous 12 -month period in 13-14-year-old children) was used as the prevalence of clinical asthma. Accordingly they reported that the mean prevalence of clinical asthma for the Middle East was 5.8\%, and for the Mediterranean was 3.9\%. However hyperresponsiveness is the most common test used to confirm asthma diagnosis in a clinical setting but not in the general population. Hyper-responsiveness is not a good marker for asthma in populations (as opposed to a clinical setting in patients describing asthma symptoms) and questionnaire-based prevalence is an appropriate methodology for epidemiological studies, which is the case for ISAAC and the ECRHS $[12,13]$.

The language used for the questionnaire in our study was Arabic. Miller et al. studied the accuracy of the Arabic version of ISAAC [14]. Their study compared physician diagnosis of asthma in children reporting current wheeze in the video or written questionnaires. In this context the written questionnaire showed good agreement with physician diagnosis, except for the question about exercise-induced asthma symptoms.

In inner-city schools in the United States of America, a survey using a brief questionnaire derived from the ISAAC wheezing questionnaire showed $60 \%$ underdiagnosis of asthma. After validation of the diagnosis by a physician the authors concluded that school screening of asthma by questionnaire is a valid tool even in deprived populations and regardless of the language [15].
Crane et al. published a paper on behalf of the ISAAC Phase One study group about the degree of agreement between the written and video questionnaires, focusing on current wheeze and comparing the results between regions, language groups and centres [16]. They concluded that the video questionnaire gave lower prevalence estimates, but the overall correlation between the measures was good. The proportion of agreement was high (mean 0.89 ). The chance-corrected agreement measured using the kappa coefficient varied between centres ( 0.45 to 0.10 ). In our Syrian centres the corresponding kappa value for current wheeze was 0.22 . Crane et al. concluded that the ISAAC core written questionnaire is a valuable tool for comparison of data between centres and for examining time trends. These results were used by the State of world allergy report 2008 [5].

Van Sickle noted that in developing countries which have a high burden of respiratory diseases other than asthma, the ISAAC video questionnaire may be helpful for training practitioners to improve their diagnosis and management of asthma [17].

A more challenging issue is that the prevalence of severe speech-limiting wheeze ranged from $2.0 \%-2.3 \%$ for the 6-7-year-olds and $2.0 \%-3.5 \%$ and for 13-14-year-olds, and the prevalence of sleep disturbance once or more per week ranged from $2.9 \%-5.3 \%$ in pupils aged 6-7 years and from $2.6 \%-4.5 \%$ of pupils aged 13-14 years in these Syrian cities. This is alarming because the symptoms experienced by these children indicate that their asthma is not under control. Other countries of the region have a similar prevalence of severe symptoms, indicating poor management of asthma [1].

The prevalence of asthma in the Eastern Mediterranean Region is high and deserves consideration as a public health priority, in concordance with the WHO resolution in the year 2000 identifying chronic respiratory diseases 
as a public health priority [18]. Consequently we conclude that large-scale programmes to improve diagnosis in a cost-effective manner are needed. Regional programmes such as GINA [19], and WHO programmes such as the Global Alliance against Respiratory Diseases and the Practical Approach to Lung Health $[18,20]$ could lead the way.

Variations in asthma prevalence cannot be explained only by genetic factors $[1,21]$. While the analysis of the global ISAAC Phase Three environmental questionnaire data by the IIDC is not yet complete, other studies however have shown a negative association with increased numbers of siblings [21,22] and positive associations with less traditional lifestyles and the consumption of fast-foods [23]. Exposure to environmental tobacco smoke in the home is another reported risk factor [24].

Lifestyle and environmental factors cannot be discounted as possible causes of the high prevalences noted in the present study [1,21].

\section{Conclusions}

The prevalence of current asthma in selected cities of the Syrian Arab Republic ranged from $4.7 \%$ to $5.7 \%$ for 6-7-year-olds and 3.9\% to $6.5 \%$ for 13-14-year-olds. These results form the basis for future local, national and international comparisons and research in order to explain the reasons for this variability of prevalence between countries.

\section{References}

1. Masoli M et al. Global burden of asthma 2004. Geneva, Global Initiative for Asthma, 2004 (http://www.ginasthma.com/reportltem. asp? $11=2 \& \mid 2=2 \&$ intld=94, accessed 22 March 2010).

2. ISAAC Steering Committee. Worldwide variations in the prevalence of asthma symptoms: the International Study of Asthma and Allergies in Childhood (ISAAC). European Respiratory Journal, 1998, 12(2):315-335.

3. Asher $\mathrm{M}$ et al. International study of asthma and allergies in childhood (ISAAC): rationale and methods. European Respiratory Journal, 1995, 8(3):483-491.

4. International Study of Asthma and Allergies in Childhood manual, 2nd ed. Auckland, ISAAC Steering Committee, 1993 (http:// isaac.auckland.ac.nz/phases/phaseone/phaseonemanual. pdf, accessed 22 March 2010).

5. Pawankar R et al. State of World Allergy Report 2008: allergy and chronic respiratory diseases. World Allergy Organization Journal, 2008, 1(6):S4-17.

6. Weiland SK, et al. Phase II of the International Study of Asthma and Allergies in Childhood (ISAAC II): rationale and methods. European Respiratory Journal, 2004, 24(3):406-412.

7. Mohammad Y et al. ISAAC phase III-Syrie [abstract]. Revue des Maladies Respiratoires, 2006, 23:10S3.

8. Tabbak K. Prevalence of asthma and allergies in children in Aleppo. Research Journal of Aleppo University, Medical Series, 2006, 51:41-62.

9. Ellwood P et al. ISAAC phase three manual. Auckland, ISAAC International Data Centre, 2000.

10. International Study of Asthma and Allergies in Childhood [website] (http://isaac.auckland.ac.nz, accessed 22 March 2010).

11. Asher $\mathrm{Ml}$ et al. Worldwide time trends in the prevalence of symptoms of asthma, allergic rhinoconjunctivitis, and eczema in childhood: ISAAC phases one and three repeat multicountry cross-sectional surveys. Lancet, 2006, 368:733-743.

12. De Marco R et al. An undetected burden of asthma in Italy: the relationship between clinical and epidemiological diagnosis of asthma. European Respiratory Journal, 1998, 11(3):599-605.
13. Pearce N, Beasley R, Pekkanen J. Role of bronchial responsiveness testing in asthma prevalence surveys. Thorax, 2000, 55(5):352-354.

14. Miller CJ et al. Accuracy of Arabic versions of three asthma symptoms questionnaires against the clinical diagnosis of asthma. Journal of Asthma, 2007, 44(1):29-34.

15. Galant SP et al. Predictive value of a cross-cultural asthma casedetection tool in an elementary school population. Pediatrics, 2004, 114(3):e307-e316.

16. Crane J et al. Agreement between written and video questions for comparing asthma symptoms in ISAAC. European Respiratory Journal, 2003, 21(3):455-461.

17. Van Sickle D. Perceptions of asthma among physicians: an exploratory study with the ISAAC video. European Respiratory Journal, 2005, 26(5):829-834.

18. Bousquet J et al. Global surveillance, prevention and control of chronic respiratory diseases: a comprehensive approach. Geneva, World Health Organization, 2007.

19. Global Initiative for Asthma [website] (http://www.ginasthma. com/index.asp, accessed 22 March 2010).

20. Practical Approach to Lung Health. Manual on initiating PAL implementation. Geneva, World Health Organization, 2008 (WHO/HTM/TB/2008.410, WHO/NMH/CHP/CPM/08.02).

21. Pearce N, Douwes J. The global epidemiology of asthma in children. International Journal of Tuberculosis and Lung Disease, 2006, 10(2):125-132.

22. Al-Kubaisy W, Ali SH, Al-Thamiri D. Risk factors for asthma among primary school children in Baghdad, Iraq. Saudi Medical Journal, 2005, 26(3):460-466.

23. Wickens $\mathrm{K}$ et al. Fast foods-are they a risk factor for asthma? Allergy, 2005, 60(12):1537-1541.

24. Mitchell EA et al. The ecological relationship of tobacco smoking to the prevalence of symptoms of asthma and other atopic diseases in children: the International Study of Asthma and Allergies in Childhood (ISAAC). European Journal of Epidemiology, 2001, 17(7):667-673. 